OPEN ACCESS

Edited by:

Tatjana Rundek,

University of Miami, United States

Reviewed by:

Jose Gutierrez,

Columbia University, United States

Ana Cristina Jacobowski,

Federal University of Mato Grosso do Sul, Brazil

*Correspondence:

Dearbhla M. Kelly

dkelly28@mgh.harvard.edu

Specialty section:

This article was submitted to

Dementia and Neurodegenerative

Diseases,

a section of the journa

Frontiers in Neurology

Received: 06 December 2021

Accepted: 03 February 2022

Published: 25 February 2022

Citation:

Kelly DM and Rothwell PM (2022)

Disentangling the Relationship Between Chronic Kidney Disease and

Cognitive Disorders.

Front. Neurol. 13:830064.

doi: 10.3389/fneur.2022.830064

\section{Disentangling the Relationship Between Chronic Kidney Disease and Cognitive Disorders}

\author{
Dearbhla M. Kelly ${ }^{1 *}$ and Peter M. Rothwell ${ }^{2}$ \\ ${ }^{1}$ J. Philip Kistler Stroke Research Center, Department of Neurology, Massachusetts General Hospital, Harvard Medical \\ School, Boston, MA, United States, ${ }^{2}$ Wolfson Center for Prevention of Stroke and Dementia, Nuffield Department of Clinical \\ Neurosciences, John Radcliffe Hospital, University of Oxford, Oxford, United Kingdom
}

Chronic kidney disease (CKD) is a rapidly rising global health burden that affects nearly $40 \%$ of older adults. Epidemiologic data suggest that individuals at all stages of chronic kidney disease (CKD) have a higher risk of developing cognitive disorders and dementia, and thus represent a vulnerable population. It is currently unknown to what extent this risk may be attributable to a clustering of traditional risk factors such as hypertension and diabetes mellitus leading to a high prevalence of both symptomatic and subclinical ischaemic cerebrovascular lesions, or whether other potential mechanisms, including direct neuronal injury by uraemic toxins or dialysis-specific factors could also be involved. These knowledge gaps may lead to suboptimal prevention and treatment strategies being implemented in this group. In this review, we explore the mechanisms of susceptibility and risk in the relationship between CKD and cognitive disorders.

Keywords: CKD, dialysis, hypertension, cognitive impairment, dementia, stroke

\section{INTRODUCTION}

The global burden of chronic kidney disease (CKD) is rising with estimated prevalence rates of $11-13 \%$ (1), increasing to nearly $40 \%$ in persons aged $60+$ years (2). Although its contribution to cardiovascular diseases is well-established (3), the significant impact of CKD on cognitive brain health is only beginning to emerge. CKD is strongly associated with both cognitive impairment and dementia, and these associations worsen with declining renal function (4). In this review, we will discuss the clustering of risk factors associated with dementia in this group as well as the potential role of novel renal-specific factors. We will endeavor to tease out the role of these putative risk factors and mechanisms as mediators, confounders, or epiphenomena.

\section{KIDNEY-BRAIN AXIS}

The kidney-brain axis refers to a relationship that exists under both physiological and pathophysiological circumstances. This relationship has been described as the "neglected kidneybrain axis" (5) because the critical interplay between these two organs that can lead to important neurological disease pathophysiology has only recently been recognized. The kidney and brain share similar anatomical and physiological features that render them vulnerable to the impact of traditional cardiovascular risk factors such as hypertension, diabetes, and smoking (6). Both organs share a low vascular resistance system, allowing continuous high-volume perfusion (7). Autoregulation allows constant blood flow despite fluctuations in blood pressure, to maintain 
cerebral perfusion pressure in the brain and GFR in the kidney. The "strain vessel hypothesis" has been proposed as a possible mechanism for the relationship between renal and cerebrovascular diseases whereby juxtamedullary afferent arterioles in the kidney and cerebral perforating arteries are both exposed to high pressure and have to maintain large pressure gradients, rendering them uniquely susceptible to hypertensive injury (8). This hypertensive vascular injury is then clinically manifest as proteinuria and progressive GFR decline in the kidney, and as symptomatic stroke, silent cerebral small vessel disease and cognitive decline in the brain.

It has also been hypothesized that there may be inflammatory cross-talk between the two organs that may also contribute to the cerebrovascular and neuropsychiatric disease burden observed in patients with CKD (9). This cross-talk between the kidney and brain may include enhanced cytokine/chemokine release and production of reactive oxygen species (ROS) in AKI or CKD leading to neuroinflammation, cytokine interaction with pathogenic neurotrophic factors through a disrupted blood-brain barrier, and activation of the brain renin-angiotensin system (RAS) contributing to oxidative stress via angiotensin II. The cytokines/chemokine release in CKD activates immune cells, neurons, and glial cells in the brain creating a cascade with release of more inflammatory molecules, which locally interact with neurotrophic factors and with ROS, thus contributing to neuropsychiatric disorders.

\section{EPIDEMIOLOGY OF COGNITIVE DISORDERS IN CKD}

The prevalence of MCI in pre-dialysis CKD is reported as variably being between 25 and $62 \%(10,11)$, compared to rates of $11-$ $26 \%$ in the matched general population $(10,12)$. In the Reasons for Geographic and Racial Differences in Stroke (REGARDS) Study, each $10 \mathrm{~mL} / \mathrm{min} / 1.73 \mathrm{~m}^{2}$ decrease in eGFR $<60 \mathrm{~mL} / \mathrm{min} /$ $1.73 \mathrm{~m}^{2}$ was associated with an $11 \%$ increase in prevalence of cognitive dysfunction (13). Haemodialysis patients are three times more likely to have severe cognitive impairment than agematched non-dialysis patients with reported prevalence rates of $30-40 \%$ (14).

$\mathrm{CKD}$ is in fact one of the strongest risk factors for mild cognitive impairment (MCI) and dementia as demonstrated by a recent 6-year population-based longitudinal study in which the impact of CKD on risk of MCI and dementia was exceeded only by stroke and chronic use of anxiolytics (15). Even early stages of CKD are associated with cognitive impairment (16). In a pediatric study of 340 patients (ages 6-21) with mild-moderate $\mathrm{CKD}$, a longer duration of CKD was associated with reduced attention and executive function, with a doubling of the odds of poor performance for every 4.6 years of disease exposure (17). However, in the Three-City (3C) Study, a longitudinal cohort of 9,294 adults aged 65 years and over, although the cross-sectional findings suggested that duration of disease was more relevant than the level of GFR; in the longitudinal analysis, rapid eGFR decline $\left(>4 \mathrm{ml} / \mathrm{min} / 1.73 \mathrm{~m}^{2} / \mathrm{yr}\right)$ was more strongly associated with cognitive decline and incident dementia (18). It may be the case that duration of CKD is particularly relevant in children and adolescents during periods of critical neurodevelopment (19).

In another recent, large population-based study, CKD was associated with a higher dementia risk [hazard ratio (HR), 1.71; 95\% confidence interval (CI)], 1.54-1.91 in eGFR 30-59 ml/min and HR 2.62, $1.91-3.58$ in eGFR $<30 \mathrm{ml} / \mathrm{min}$ ] compared with eGFR of $90-104 \mathrm{ml} / \mathrm{min}$ (20). In this study, both the severity of CKD and steeper kidney function decline were associated with dementia. It was found that as many as $10 \%$ (95\% CI 6$14 \%$ ) of dementia cases could be attributed to CKD, a proportion higher than that attributed to other dementia risk factors such as cardiovascular disease and diabetes.

As a measure of kidney function, proteinuria also appears to be more strongly associated with cognitive decline than low eGFR for reasons that are unclear $(21,22)$. This finding is however consistent with recently published meta-analyses data on the relationship between low eGFR, proteinuria, and stroke risk $(23,24)$.

The prevalence of dementia among haemodialysis patients is $8-37 \%$ with the risk increasing linearly with age $(12,25)$. Prevalence rates are broadly similar (4-33\%) for patients on maintenance peritoneal dialysis $(12,26)$ but fall for kidney transplant recipients $(7-22 \%)(27,28)$. Although there may be a selection bias in terms of transplant candidates, improvements in cognitive scores in parallel with favorable structural and functional changes in white matter integrity have been described 1 year after kidney transplantation (29). However, these changes may not be sustained in frail recipients (27). Older adults on haemodialysis with a diagnosis of Alzheimer's disease or dementia have a $>2$-fold risk of mortality compared to those without these diagnoses (25).

\section{MECHANISMS OF SUSCEPTIBILITY AND RISK}

Mechanisms underlying the pathogenesis of MCI and dementia in CKD are poorly understood. Both vascular and neurodegenerative hypotheses have been proposed (Figure 1) $(5,30)$. In support of the vascular hypothesis, there is a high prevalence of cardiovascular risk factors, such as hypertension and diabetes mellitus, as well as a significant burden of both symptomatic and subclinical cerebrovascular disease (31). On the contrary, consistent with the neurodegenerative hypothesis, the accumulation of uraemic toxins can cause cerebral endothelial dysfunction and has been implicated in cognitive decline (32). However, this binary view of potential pathogenesis for CKDrelated neurocognitive disorders is likely an over-simplistic summary of a multi-factorial process that likely includes elements of both hypotheses. We will outline the evidence for these cognitive risk factors, some of which are shared by the general population, and some of which are renal-specific.

\section{Age and Sex Differences}

The greatest risk factor for Alzheimer's disease (AD) is advanced age (33). Prevalence of AD shows a steep increase with age, from $0.6 \%$ in the group age $65-69$ years to $22.2 \%$ in the group aged 


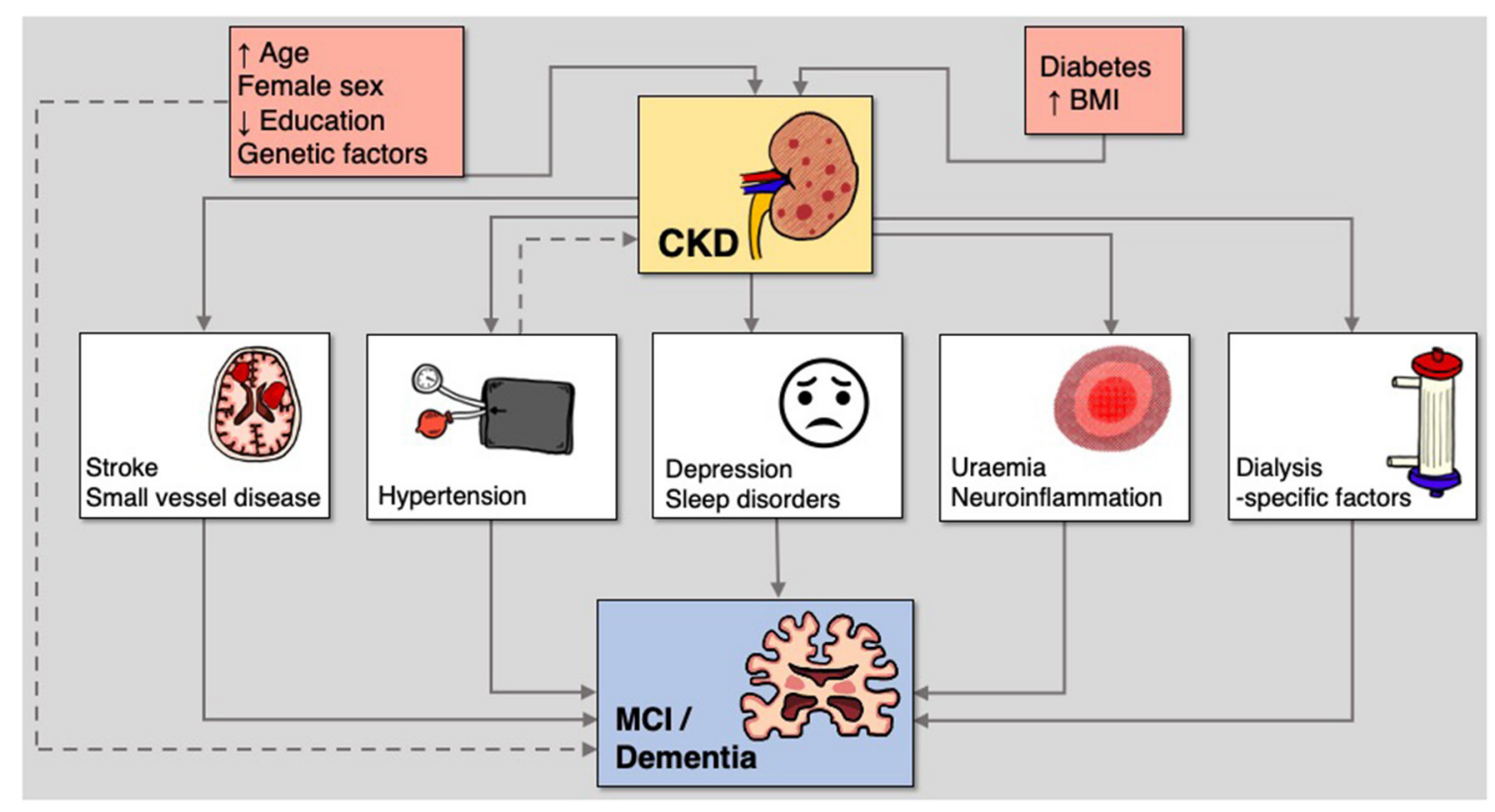

FIGURE 1 | Mechanisms of susceptibility and risk in the relationship between CKD and cognitive disorders.

90 years and older (34). Age also contributes to the etiology and progression of $\mathrm{CKD}$. The aged kidney undergoes a range of structural and functional changes that can lead to disordered inflammation and renal fibrosis, rendering the kidney vulnerable to acute insults and increasing the risk of CKD progression (35). These changes may be part of a broader process of systemic persistent inflammation causing inflammatory aging known as "inflammageing". This condition is characterized by elevated levels of blood inflammatory markers (36), a high susceptibility to cerebrovascular disease and dementia $(37,38)$, and is exacerbated by uraemia and dialysis dependency (39).

There are also key sex differences in the prevalence of both dementia and CKD. A European meta-analysis found that the pooled prevalence of $\mathrm{AD}$ was 7.02 per 1,000 person-years in men and 13.25 per 1,000 person-years in women (40). Women account for approximately two-thirds of patients with $\mathrm{AD}$ and related dementias in both Europe and the US (41, 42). This disparity is thought to be attributable to women's greater longevity since risk of developing dementia increases with age and there may be a competing mortality risk for men that can confound HR estimation of dementia $(43,44)$. However, a recent study showed that incident midlife hypertension was associated with greater memory decline in women and suggested that such discrepancies in risk factor-disease associations could also potentially contribute to heterogeneity of $\mathrm{AD}$ disease prevalence in later life (45). Similarly, several other key vascular risk factors such as hyperlipidaemia, diabetes mellitus and atrial fibrillation also appear to be associated with greater risk of stroke in women compared to men which may contribute to downstream dementia burden (46). The proportion of women with predialysis CKD is also higher than that of men, a difference that is also likely accounted for by the longer life expectancy of women, but nonetheless renders them especially vulnerable to accelerated "inflammageing" and the enhanced effects of vascular risk factors, and consequently, to diseases of brain aging such as stroke and dementia (47). Therefore, both age and sex could account for confounding and epiphenomenal association in the relationship between CKD and cognitive impairment.

\section{Education Level}

A low educational level is associated with an increased incidence of clinical AD or dementia (48). It has been suggested that education could delay the clinical expression of dementia symptoms by increasing the neocortical synaptic density (the "brain reserve" hypothesis) (49). Others have proposed that educational and occupational attainment provide a reserve against dementia, enabling this group to cope with advanced pathological changes of the disease more effectively by maintaining function longer (the "cognitive reserve" hypothesis) (50). However, it may also be the case that those with greater educational attainment and associated higher socioeconomic status may be exposed to fewer neurotoxins and have fewer cardiovascular risk factors that may contribute to vascular/neurodegenerative brain disorders (the "brain battering" hypothesis) (51).

Similarly, low educational and occupational levels have been associated with CKD and worse kidney outcomes (52). CKD risk, albuminuria, and reduced eGFR rates are all higher among participants with low educational level compared to those with high educational level. Exploratory longitudinal mediation analysis suggest that the association between education and CKD can partly be explained by diabetes and the modifiable risk factors, body mass index (BMI), waist-to-hip ratio (WHR), smoking, potassium and hypertension (53). Thus, low 
educational attainment is another potential confounder in the association between $\mathrm{CKD}$ and cognitive disorders with some evidence of synergy as subtle GFR decline is associated with more rapid cognitive decline in those with lower educational levels (54). However, more recent data in the general population suggests that higher cognitive reserve may not diminish the adverse effects of covert vascular brain injury (55).

\section{Hypertension}

The causal relationships between hypertension, CKD and dementia are particularly complex as hypertension could be potentially both a confounder and mediator in the relationship between CKD and dementia.

Many observational studies report hypertension to be an important risk factor for dementia (56-58) and in a recent meta-analysis of randomized clinical trials, blood pressure lowering with antihypertensive agents compared with control was significantly associated with a lower risk of incident dementia or CI (59). The relationship between hypertension and cognitive decline may be mediated through cerebrovascular disease (60, 61) or via augmentation of neurodegenerative mechanisms. At autopsy, hypertensive older adults also have evidence of greater $\mathrm{AD}$ pathology in the brain, including neurofibrillary tangles and neuritic amyloid-beta (A $\beta$ ) plaques (62). Positron emission tomography studies have shown that the extent of $A \beta$ deposition in the brain is positively associated with higher BP (63). The chronicity of past hypertension appears to be most important. Multiple studies have indicated that it is the occurrence of midlife hypertension and its persistence into late life that is one of the leading risk factors for late-life dementia $(64,65)$.

It follows then that since hypertension occurs in 67$92 \%$ of patients with CKD (66), that the adverse cognitive consequences could be accentuated in this group. However, although premorbid mid-life to late-life blood pressure is strongly associated with MCI and dementia in the general population, its role in dementia pathogenesis in $\mathrm{CKD}$ is unknown. A recent systematic review and meta-analysis of stroke risk in CKD suggested that most of the risk in this setting may be attributable to long-term blood pressure burden (23). Premorbid blood pressure may therefore also play a similarly central role in the etiology of cognitive dysfunction in CKD, though this has not been previously shown. In an analysis of 8,563 hypertensive adults in the SPRINT trial, they found that a $\geq 30 \%$ decline in baseline eGFR and incident eGFR $<60 \mathrm{ml} / \mathrm{min} / 1.73 \mathrm{~m}^{2}$ were associated with an increased incidence of probable dementia and MCI, independent of the intensity of hypertension treatment (67). This highlights a potential synergy between hypertension and kidney disease in the pathogenesis of CI and dementia.

\section{Stroke}

Stroke is associated with an increased risk of subsequent dementia. In a large meta-analysis of symptomatic stroke patients, $10 \%$ of patients had dementia before first stroke, $10 \%$ developed new dementia soon after first stroke, and more than a third had dementia after recurrent stroke (68).

There are also strong associations reported between CKD and cerebrovascular disease (30). Meta-analyses of cohort studies and trials indicate that reduced GFR is associated with a $40 \%$ greater risk of stroke and that proteinuria is associated with a $70 \%$ greater risk (69) even after adjusting for traditional cardiovascular risk factors. In terms of potential mechanisms, there is a high prevalence of shared vascular risk factors including hypertension, diabetes mellitus, and atrial fibrillation but "nontraditional" risk factors such as anemia, hyperuricemia, and mineral-bone disorders may also play a role (70).

Importantly, several of the predictors of post-stroke dementia (68) are common in the CKD population including older age (35), low educational attainment (52), premorbid disability, (71) and vascular risk factors such as diabetes mellitus and atrial fibrillation (AF) (72). In addition, CKD is associated with several stroke-specific factors (68) that are predictive of post-stroke dementia including higher stroke severity and greater risk of recurrence (73).

\section{Small Vessel Disease}

Cerebral small vessel disease (SVD) is a major etiologic factor in dementia (74). This may relate to a reduction in cerebral blood flow (75), and impaired cerebral autoregulation (76). SVD and $\mathrm{AD}$ pathology are thought to interact in important ways (77). Chronic cerebral inflammation due to vascular risk factors exposure and genetic modulators (apoE4) may lead to increase $\mathrm{A} \beta$ production while chronic SVD (arteriosclerosis, cerebral amyloid angiopathy) and vascular inflammation may drive inefficient perivascular and cell-mediated $A \beta$ clearance (78).

SVD is highly prevalent in patients with CKD (79) and it is associated with all subtypes including white matter lesions (WML) (80), silent cerebral infarctions (SCI) (81), perivascular spaces (PVS) (82), and cerebral microbleeds (CMB) (83). Over half of all CKD or dialysis-dependent patients have evidence of SCI on imaging studies $(84,85)$. These associations may relate to the "strain vessel hypothesis" (8), shared cardiovascular risk factor burden (81), or perhaps genetic pleiotropy may play a role in younger populations (86). SCI in the presence of CKD has been associated with executive dysfunction (87). This pattern of cognitive change with prominent impairment of executive function and processing speed has also been observed in maintenance haemodialysis patients (88), consistent with cognitive deficits associated with cerebrovascular disease (89). It is therefore unclear whether CKD is a risk factor for dementia independent of either symptomatic or subclinical cerebrovascular disease.

\section{Diabetes Mellitus and Obesity}

A recent meta-analysis of over 2 million participants showed that individuals with type 2 diabetes are at $\sim 60 \%$ greater risk for the development of dementia compared with those without diabetes (90). Those with a younger age of diabetes onset and cardiovascular comorbidity are particularly at risk (91). Several mechanisms for the link between diabetes and dementia have been proposed including brain metabolic dysfunction as a driver for AD pathology (92), with impairments in insulin transport through the blood-brain barrier, insulin signaling, and resultant decreased cerebral glucose utilization (93). In addition, hyperglycemia may lead to neurotoxicity, vascular injury, and 
accumulation of advanced glycation end products (94). Nearly one third of CKD is attributable to diabetic nephropathy (3) and even patients with mild-moderate stages of diabetic kidney disease have been found to have occult neurocognitive disorders (95), highlighting the role of diabetes as a potential confounding factor in this pathway.

Increasing evidence suggests that obesity, highly prevalent in the CKD population (96) and estimated to account for $\sim 20$ $25 \%$ of kidney disease worldwide (97), is also an independent risk factor for dementia. In an analysis of 6,582 participants from the English Longitudinal Study of Aging, individuals with baseline obesity had about a 30\% increased risk of dementia even after adjusting for sex, baseline age, apolipoprotein E- $\varepsilon 4$ (APOE- $\varepsilon 4$ ), education, physical activity, smoking, marital status, hypertension and diabetes (98). Similar to diabetes though, excess adiposity is linked with a change in brain energy metabolism, the accumulation of brain lesions and brain volume loss leading to neurodegeneration (99).

\section{Depression and Sleep Disorders}

Approximately 25\% of CKD patients report symptoms of a major depressive disorder (100) with high rates of undertreatment described (101). In particular, hemodialysis patients with a greater burden of depressive symptoms perform worse on tests of cognition related to processing speed and executive function, suggesting that depression could therefore be a potential mediating or contributing factor in the relationship between CKD and cognitive disorders (102).

Similarly, sleep disorders are highly prevalent in CKD with a spectrum of manifestations described including insomnia, sleep fragmentation, daytime somnolence, sleep apnoea, altered circadian rhythm, and restless legs syndrome (103). Sleep disorders are also highly linked to cognitive impairment and dementia and are often representative of underlying brain pathology (104). The glymphatic system is responsible for clearance of $\sim 60 \%$ of $\beta$-amyloid clearance and since this occurs primarily during sleep (105), which is altered during CKD, it has been proposed that glymphatic fluid transport may be suppressed in CKD, leading to an accumulation of potentially neurotoxic waste products (106).

\section{Genetic Factors}

The role of genetic factors in the pathogenesis of cognitive dysfunction in CKD has been largely unexplored (106). In younger patients, some rare genetic syndromes have been described that can cause both kidney disease as well as neurocognitive disorders including tuberous sclerosis (107), Fabry disease (108), and Bardet-Biedl Syndrome (109). In general, compared with noncarriers, children with genetic kidney disease score significantly poorer on all measures of intelligence, anxiety/depressive symptoms, and executive function (110).

A genetic cause has been described in $10 \%$ of adult patients with CKD (111), and this figure can rise to $37 \%$ of those with positive family history, many of whom have extra-renal features (112). However, it is not known whether there is a similar tendency toward neurocognitive disorders in this group. Several single-nucleotide polymorphisms (SNPs) associated with kidney disease (113) are in exons for genes that also expressed in the brain including in the striatum (SLC47A1, KLHDC7A and SLC25A45; from the Allen Brain Atlas database), cortex (EDEM3, PPM1J, and CERS2; from the Human Protein Atlas database) and the cerebellum and hippocampus (TSPAN9 and EPB41L5; from the Human Protein Atlas database). Furthermore, some are in genes linked to Alzheimer's disease (CACNA1S; WikiPathways database).

Two genome-wide association studies have also previously indicated genetic pleiotropy between kidney and cerebrovascular disease, particularly with large artery atherosclerotic and small vessel stroke $(86,114)$. In the most recent of these studies that leveraged large-scale data from international consortia, a locus at $2 \mathrm{q} 33$ showed pairwise associations between urinary albumin:creatinine ratio and both small vessel stroke and white matter hyperintensities (WMH), indicating that 2q33 may play a role across small vessel pathologies in both the kidney and brain through microalbuminuria, small vessel stroke, and $\mathrm{WMH}$, and that there may be a shared common pathway among cerebral and renal manifestations of small vessel disease (114).

\section{Uraemia and Neuroinflammation}

The accumulation of uraemic toxins is proposed to cause cerebral endothelial dysfunction and contribute to cognitive disorders in CKD (32). High uraemic toxin concentrations of guanidine compounds such as creatinine, guanidine, guanidinosuccinic acid, and methylguanidine have been found in CKD patients in strategic brain regions for cognition, such as the thalamus, mammillary bodies, and cerebral cortex (115). Haemodialysis efficiently eliminates water-soluble toxins and improves acute uraemic encephalopathy, but is relatively ineffective for proteinbound or medium-sized toxins that may contribute to chronic cognitive dysfunction in patients with ESKD (106). Of particular interest is Neuropeptide Y, a polypeptide that has been implicated in some neurodegenerative and neuroimmune disorders (116), and that is also present in high levels in CKD (117).

Inflammation has also been suggested as a mediator of cognitive decline in CKD (118). The intensity of systemic inflammation, as indicated by elevations in multiple markers of inflammation, including interleukin-1 $\beta$ (IL-1 $\beta$ ), interleukin-6 (IL-6), tumor necrosis factor- $\alpha$ (TNF- $\alpha$ ), and C-reactive protein (CRP), appears to increase as kidney function declines (119). Both cross-sectional and longitudinal studies have shown that that CRP and fibrinogen are independently associated with deterioration in some domains of cognitive function in patients with CKD $(120,121)$, though these studies are vulnerable to type 1 error from multiple testing.

\section{Dialysis-Specific Factors}

It is increasingly recognized that haemodialysis is associated with both acute and chronic brain injury $(122,123)$. Even in clinically stable patients undergoing intermittent haemodialysis, it can cause cerebral oedema via an increase in brain water content and from reverse osmotic shift due to urea (124) or other newly formed brain osmoles (125). Global cerebral blood flow has 


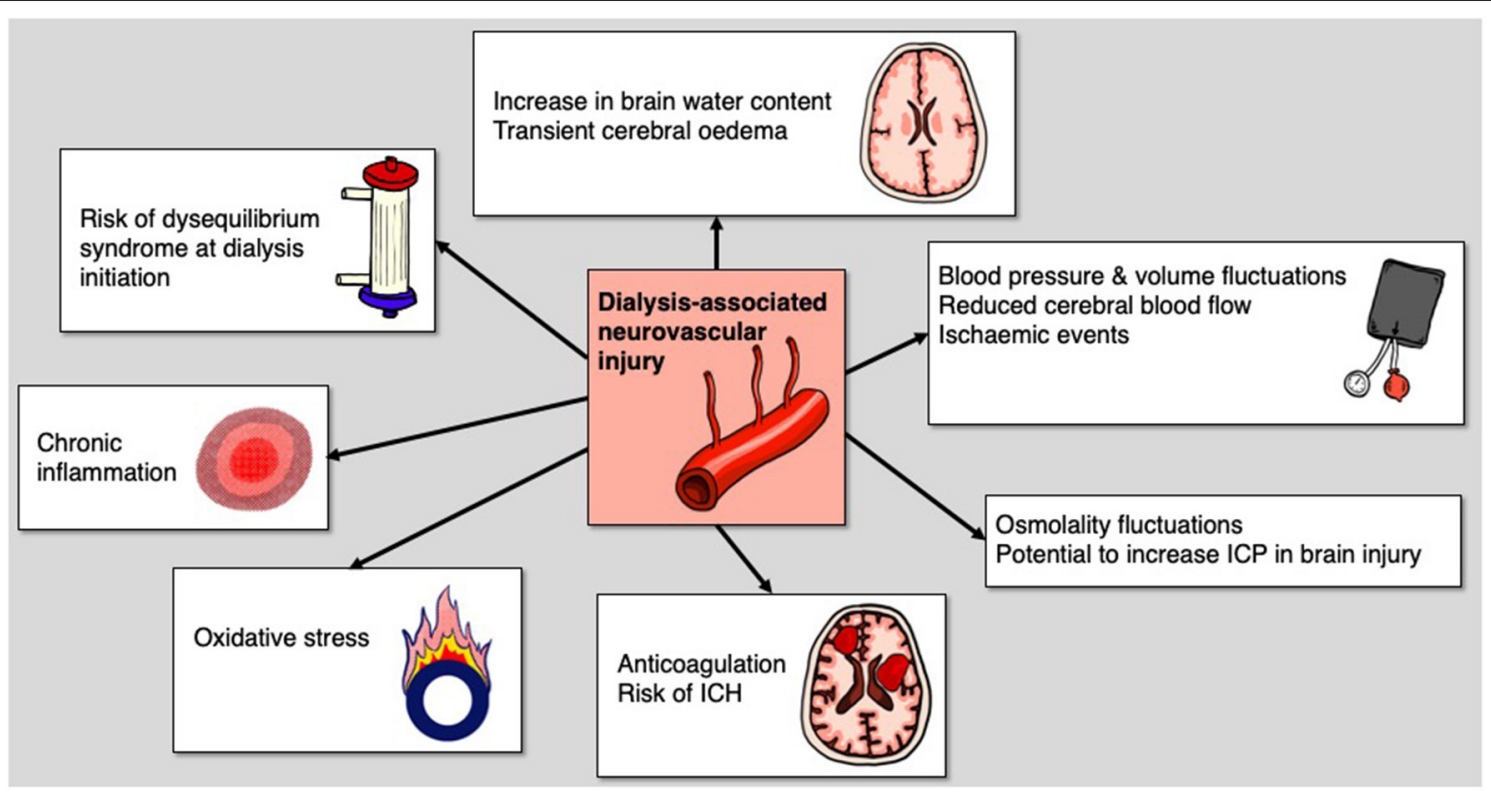

FIGURE 2 | The potential impact of dialysis-associated neurovascular injury on cognition.

also been shown to decline acutely by $10 \%$ during hemodialysis (126). Thus, in the setting of acute brain injury, there is a risk of secondary brain injury in what's now referred to as dialysisassociated neurovascular injury (DANI) (Figure 2) (122).

In the chronic setting, it has been shown that every $10 \mathrm{mmHg}$ drop from baseline in mean arterial pressure during a dialysis session is associated with a $3 \%$ increase in ischaemic events (127). Nearly one-quarter of haemodialysis sessions feature cerebral ischaemic events and these intradialytic events correlate with decreased executive cognitive function at 12 months.

In a prospective cohort study of about 100 chronic haemodialysis patients, cerebral arterial mean flow velocity (MFV) was demonstrated to decline significantly during dialysis and this decline correlated with intradialytic decline in cognitive function (128). Decline in MFV also correlated significantly with progression of white matter burden and cerebrovascular disease at 12 months follow-up. Haemodialysis is thus capable of inducing transient "cerebral stunning," analogous to myocardial stunning, and may be a major mechanism of cerebral injury and accelerated cognitive decline in dialysis-dependent patients.

\section{Beta-Amyloid Pathology}

The role of beta-amyloid $(A \beta)$ pathology in the relationship between $C K D$ and cognitive decline in poorly understood. Serum $\mathrm{A} \beta$ levels have been shown to be significantly higher in $\mathrm{CKD}$ patients, possibly related to reduced renal clearance of $\mathrm{A} \beta$ protein from peripheral blood (129). Cystatin-C, a low-molecular weight protein that is used to estimate GFR, has also been demonstrated to colocalize with beta-amyloid in the brain (130).

However, there is some evidence from animal and small human studies that peripheral clearance of $A \beta$ by dialysis could help to reduce the amyloid plaque burden in the brain (131). In one study, plasma $A \beta$ levels before and immediately after peritoneal dialysis in 30 patients with newly diagnosed CKD and in APP/PS1 mice were measured. In both cases, plasma $A \beta 40$ and $A \beta 42$ levels were significantly reduced after dialysis. In the animal model, $P D$ resulted in a decrease in $A \beta$ levels in the brain interstitial fluid with reduced plaque deposition. Dialysis solution appeared to account for only $10 \%$ of $\mathrm{A} \beta$ removal suggesting that the remaining clearance was mediated by efflux transport of $A \beta$ across the $B B B$ and enhancement of endogenous clearance pathways. The dialysis-treated mice showed reduced levels of hyperphosphorylated tau in the brain, suggesting a slowing of neurodegeneration along with decreased inflammation. Attenuated cognitive decline was demonstrated by improved performance on the Y-maze and open-field tests.

Brain $A \beta$ deposition also appears to be lower in maintenance haemodialysis patients (132). Clearance rates of both peptides during one haemodialysis session were $22 \%$ and $35 \%$ for $A \beta 42$ and $A \beta 40$, respectively (133). By inducing peripheral $A \beta$ sink and stimulating $A \beta$ efflux from the brain, it has been suggested that haemodialysis could be considered as an anti-amyloid treatment strategy.

\section{CONCLUSIONS}

CKD is strongly associated with MCI and dementia, and the pathogenesis is likely multifactorial, incorporating elements of both vascular disease as well as neurodegenerative processes. Patients with CKD appear to have a clustering of susceptibility and risk factors associated with dementia including lower cognitive reserve (advancing age, lower educational and occupational attainment), cardiometabolic risk factors (hypertension, diabetes, obesity, stroke), neuropsychiatric comorbidities (depression, sleep disorders) and renal-specific factors (uraemia, inflammation, intradialytic "cerebral 
stunning"). From an epidemiological perspective, it remains challenging to disentangle independently causal associations from intermediate mediators, confounders, and epiphenomena. Further research is needed to fully elucidate the role of genetic factors and $\mathrm{A} \beta$ pathology in this relationship. In an aging population, targeting novel modifiable risk factors such as CKD and associated multimorbidity may help reduce the global burden of dementia.

\section{AUTHOR CONTRIBUTIONS}

DK drafted the manuscript for intellectual content. PR contributed to the format and revised the manuscript for

\section{REFERENCES}

1. Hill NR, Fatoba ST, Oke JL, Hirst JA, O'Callaghan CA, Lasserson DS, et al. Global prevalence of chronic kidney disease - a systematic review and metaanalysis. PLoS ONE. (2016) 11:e0158765. doi: 10.1371/journal.pone.0158765

2. Coresh J, Astor BC, Greene T, Eknoyan G, Levey AS. Prevalence of chronic kidney disease and decreased kidney function in the adult US population: third national health and nutrition examination survey. Am J Kidney Dis. (2003) 41:1-12. doi: 10.1053/ajkd.2003.50007

3. Global, regional, and national burden of chronic kidney disease, 1990-2017: A systematic analysis for the global burden of disease study 2017. Lancet (London, England). (2020) 395:709-33. doi: 10.1016/S0140-6736(20)30045-3

4. Harhay MN, Xie D, Zhang X, Hsu CY, Vittinghoff E, Go AS, et al. Cognitive impairment in non-dialysis-dependent CKD and the transition to dialysis: findings from the chronic renal insufficiency cohort (CRIC) study. Am J Kidney Dis. (2018) 72:499-508. doi: 10.1053/j.ajkd.2018.02.361

5. Bugnicourt JM, Godefroy O, Chillon JM, Choukroun G, Massy ZA. Cognitive disorders and dementia in CKD: The neglected kidney-brain axis. J Am Soc Nephrol. (2013) 24:353-63. doi: 10.1681/ASN.2012050536

6. Izzo JL SD, Black HR. Hypertension primer: The essentials of high blood pressure: Basic science, population science, and clinical management. Philadelphia: Lippincott Williams \& Wilkins (2007).

7. O'Rourke MF, Safar ME. Relationship between aortic stiffening and microvascular disease in brain and kidney: cause and logic of therapy. Hypertension. (2005) 46:200-4. doi: 10.1161/01.HYP.0000168052.00426.65

8. Ito S, Nagasawa T, Abe M, Mori T. Strain vessel hypothesis: a viewpoint for linkage of albuminuria and cerebro-cardiovascular risk. Hypertens Res. (2009) 32:115-21. doi: 10.1038/hr.2008.27

9. Miranda AS, Cordeiro TM, Dos Santos Lacerda Soares TM, Ferreira RN, Simões ESAC. Kidney-brain axis inflammatory cross-talk: From bench to bedside. Clin Sci. (2017) 131:1093-105. doi: 10.1042/CS20160927

10. Burns CM, Knopman DS, Tupper DE, Davey CS, Slinin YM, Lakshminarayan $\mathrm{K}$, et al. Prevalence and risk of severe cognitive impairment in advanced chronic kidney disease. J Gerontol Ser A Biol Sci Med Sci. (2018) 73:393-9. doi: 10.1093/gerona/glx241

11. Otobe $\mathrm{Y}$, Hiraki $\mathrm{K}$, Hotta $\mathrm{C}$, Nishizawa $\mathrm{H}$, Izawa KP, Taki $\mathrm{Y}$, et al, Mild cognitive impairment in older adults with pre-dialysis patients with chronic kidney disease: Prevalence and association with physical function. Nephrology (Carlton). (2019) 24:50-5. doi: 10.1111/nep.13173

12. Kalirao P, Pederson S, Foley RN, Kolste A, Tupper D, Zaun D, et al. Cognitive impairment in peritoneal dialysis patients. Am J Kidney Dis. (2011) 57:612-20. doi: 10.1053/j.ajkd.2010.11.026

13. Kurella Tamura M, Wadley V, Yaffe K, McClure LA, Howard G, Go R, et al. Kidney function and cognitive impairment in US adults: the reasons for geographic and racial differences in stroke (REGARDS) study. Am J Kidney Dis. (2008) 52:227-34. doi: 10.1053/j.ajkd.2008.05.004

14. Murray AM, Tupper DE, Knopman DS, Gilbertson DT, Pederson SL Li S, et al. Cognitive impairment in hemodialysis patients is common. Neurology. (2006) 67:216-23. doi: 10.1212/01.wnl.0000225182.15532.40 intellectual content. Both authors contributed to the article and approved the submitted version.

\section{FUNDING}

DK is an Atlantic Fellow for Equity in Brain Health at the Global Brain Health Institute (GBHI) and is supported with funding from GBHI, Alzheimer's Association, and Alzheimer's Society (GBHI ALZ UK-22-868940). DK is also the recipient of an NIH StrokeNet Fellowship. PR has received funding from Wellcome Trust, Wolfson Foundation, British Heart Foundation, National Institute for Health Research, and the National Institute for Health Research Oxford Biomedical Research Center.

15. Lipnicki DM, Crawford J, Kochan NA, Trollor JN, Draper B, Reppermund $\mathrm{S}$, et al. Risk factors for mild cognitive impairment, dementia and mortality: The Sydney memory and ageing study. J Am Med Dir Assoc. (2017) 18:38895. doi: 10.1016/j.jamda.2016.10.014

16. Brodski J, Rossell SL, Castle DJ, Tan EJ. A systematic review of cognitive impairments associated with kidney failure in adults before natural age-related changes. J Int Neuropsychol Soc. (2019) 25:101-14. doi: $10.1017 /$ S1355617718000917

17. Mendley SR, Matheson MB, Shinnar S, Lande MB, Gerson AC, Butler RW, et al. Duration of chronic kidney disease reduces attention and executive function in pediatric patients. Kidney Int. (2015) 87:800-6. doi: $10.1038 /$ ki.2014.323

18. Helmer C, Stengel B, Metzger M, Froissart M, Massy ZA, Tzourio C, et al. Chronic kidney disease, cognitive decline, and incident dementia: The 3c study. Neurology. (2011) 77:2043-51. doi: 10.1212/WNL.0b013e31 $823 b 4765$

19. Giedd JN, Blumenthal J, Jeffries NO, Castellanos FX, Liu H, Zijdenbos A, et al. Brain development during childhood and adolescence: a longitudinal mri study. Nat Neurosci. (1999) 2:861-3. doi: 10.1038/13158

20. Xu H, Garcia-Ptacek S, Trevisan M, Evans M, Lindholm B, Eriksdotter $\mathrm{M}$, et al. Kidney function, kidney function decline, and the risk of dementia in older adults: a registry-based study. Neurology. (2021). doi: 10.1212/WNL.0000000000012113

21. Scheppach JB, Coresh J, Wu A, Gottesman RF, Mosley TH, Knopman DS, et al. Albuminuria and estimated GFR as risk factors for dementia in midlife and older age: Findings from the aric study. Am J Kidney Dis. (2020) 76:775-783. doi: 10.1053/j.ajkd.2020.03.015

22. Ekblad LL, Toppala S, Johansson JK, Koskinen S, Sundvall J, Rinne JO, et al. Albuminuria and microalbuminuria as predictors of cognitive performance in a general population: An 11-year follow-up study. J Alzheimers Dis. (2018) 62:635-48. doi: 10.3233/JAD-170972

23. Kelly DM, Rothwell PM. Does chronic kidney disease predict stroke risk independent of blood pressure? : A systematic review and metaregression. Stroke. (2019) 50:3085-92. doi: 10.1161/STROKEAHA.119. 025442

24. Kelly DM, Rothwell PM. Proteinuria as an independent predictor of stroke: Systematic review and meta-analysis. Int J Stroke. (2020) 15:29-38. doi: $10.1177 / 1747493019895206$

25. McAdams-DeMarco MA, Daubresse M, Bae S, Gross AL, Carlson MC, Segev DL. Dementia, Alzheimer's disease, and mortality after hemodialysis initiation. Clin J Am Soc Nephrol. (2018) 13:1339-47. doi: 10.2215/CJN.10150917

26. US Renal Data System: USRDS 2005 Annual Data Report: Atlas of EndStage Renal Disease in the United States. Bethesda, MD: National Institutes of Health, National Institute of Diabetes and Digestive and Kidney Disease (2005)

27. Chu NM, Gross AL, Shaffer AA, Haugen CE, Norman SP, Xue QL, et al. Frailty and changes in cognitive function after kidney transplantation. J Am Soc Nephrol. (2019) 30:336-45. doi: 10.1681/ASN.2018070726 
28. McAdams-DeMarco MA, Bae S, Chu N, Gross AL. Brown CHt, Oh E, et al. Dementia and Alzheimer's disease among older kidney transplant recipients. J Am Soc Nephrol. (2017) 28:1575-83. doi: 10.1681/ASN.2016080816

29. van Sandwijk MS, Ten Berge IJM, Caan MWA, Düring M, van Gool WA, Majoie C, et al. Cognitive improvement after kidney transplantation is associated with structural and functional changes on MRI. Transplant Direct. (2020) 6:e531. doi: 10.1097/TXD.0000000000000976

30. Kelly D, Rothwell PM. Disentangling the multiple links between renal dysfunction and cerebrovascular disease. J Neurol Neurosurg Psychiatry. (2020) 91:88-97. doi: 10.1136/jnnp-2019-320526

31. Cheung AK, Sarnak MJ, Yan G, Dwyer JT, Heyka RJ, Rocco MV, et al. Atherosclerotic cardiovascular disease risks in chronic hemodialysis patients. Kidney Int. (2000) 58:353-62. doi: 10.1046/j.1523-1755.2000.00173.x

32. Stinghen AE, Pecoits-Filho R. Vascular damage in kidney disease: Beyond hypertension. Int J Hypertens. (2011) 2011:232683. doi: 10.4061/2011/232683

33. Guerreiro R, Bras J. The age factor in Alzheimer's disease. Genome Med. (2015) 7:106. doi: 10.1186/s13073-015-0232-5

34. Lobo A, Launer LJ, Fratiglioni L, Andersen K, Di Carlo A, Breteler MM, et al. Prevalence of dementia and major subtypes in Europe: a collaborative study of population-based cohorts. Neurologic diseases in the elderly research group. Neurology. (2000) 54:S4-9.

35. O'Sullivan ED, Hughes J, Ferenbach DA. Renal aging: causes and consequences. J Am Soc Nephrol. (2017) 28:407-20. doi: 10.1681/ASN.2015121308

36. Ferrucci L, Fabbri E. Inflammageing: Chronic inflammation in ageing, cardiovascular disease, and frailty. Nat Rev Cardiolo. (2018) 15:505-22. doi: 10.1038/s41569-018-0064-2

37. Mészáros Á, Molnár K, Nógrádi B, Hernádi Z, Nyúl-Tóth Á, Wilhelm I, et al. Neurovascular inflammaging in health and disease. Cells. (2020) 9:1614. doi: 10.3390/cells 9071614

38. Cullen NC, Mälarstig AN, Stomrud E, Hansson O, Mattsson-Carlgren $\mathrm{N}$. Accelerated inflammatory aging in Alzheimer's disease and its relation to amyloid, tau, and cognition. Sci Rep. (2021) 11:1965. doi: 10.1038/s41598-021-81705-7

39. Cobo G, Lindholm B, Stenvinkel P. Chronic inflammation in end-stage renal disease and dialysis. Nephrol Dial Transplant. (2018) 33:iii35-iii40. doi: $10.1093 / \mathrm{ndt} / \mathrm{gfy} 175$

40. Niu H, Álvarez-Âlvarez I, Guillén-Grima F, Aguinaga-Ontoso I. Prevalence and incidence of Alzheimer's disease in Europe: A meta-analysis. Neurologia. (2017) 32:523-32. doi: 10.1016/j.nrl.2016.02.016

41. Alzheimer Europe. Dementia in Europe Yearbook 2019. Estimating the prevalence of dementia in Europe. Luxembourg: Alzheimer Europe (2019).

42. 2020 Alzheimer's disease facts and figures. Alzheimers Dement. (2020) 16:391-460. doi: 10.1002/alz.12068

43. Mielke MM, Vemuri P, Rocca WA. Clinical epidemiology of Alzheimer's disease: Assessing sex and gender differences. Clin Epidemiol. (2014) 6:37-48. doi: 10.2147/CLEP.S37929

44. Seshadri S, Wolf PA, Beiser A, Au R, McNulty K, White R, et al. Lifetime risk of dementia and Alzheimer's disease. The impact of mortality on risk estimates in the Framingham study. Neurology. (1997) 49:1498-504. doi: 10.1212/WNL.49.6.1498

45. Anstey KJ, Peters R, Mortby ME, Kiely KM, Eramudugolla R, Cherbuin $\mathrm{N}$, et al. Association of sex differences in dementia risk factors with sex differences in memory decline in a population-based cohort spanning 2076 years. Sci Rep. (2021) 11:7710. doi: 10.1038/s41598-021-86397-7

46. Peters SAE, Carcel C, Millett ERC, Woodward M. Sex differences in the association between major risk factors and the risk of stroke in the UK biobank cohort study. Neurology. (2020) 95:e2715-26. doi: 10.1212/WNL.0000000000010982

47. Carrero JJ, Hecking M, Chesnaye NC, Jager KJ. Sex and gender disparities in the epidemiology and outcomes of chronic kidney disease. Nat Rev Nephrol. (2018) 14:151-64. doi: 10.1038/nrneph.2017.181

48. Qiu C, Bäckman L, Winblad B, Agüero-Torres H, Fratiglioni L. The influence of education on clinically diagnosed dementia incidence and mortality data from the kungsholmen project. Arch Neurol. (2001) 58:20349. doi: 10.1001/archneur.58.12.2034

49. Katzman R. Education and the prevalence of dementia and Alzheimer's disease. Neurology. (1993) 43:13-20. doi: 10.1212/WNL.43.1_Part_1.13
50. Stern Y, Gurland B, Tatemichi TK, Tang MX, Wilder D, Mayeux R. Influence of education and occupation on the incidence of Alzheimer's disease. JAMA. (1994) 271:1004-10. doi: 10.1001/jama.1994.03510370056032

51. Del Ser T, Hachinski V, Merskey H, Munoz DG. An autopsy-verified study of the effect of education on degenerative dementia. Brain. (1999) $122(\mathrm{Pt}$ 12):2309-19. doi: 10.1093/brain/122.12.2309

52. Adjei DN, Stronks K, Adu D, Snijder MB, Modesti PA, Peters RJG, et al. Relationship between educational and occupational levels, and chronic kidney disease in a multi-ethnic sample- the helius study. PLoS ONE. (2017) 12:e0186460. doi: 10.1371/journal.pone.0186460

53. Thio CHL, Vart P, Kieneker LM, Snieder H, Gansevoort RT, Bültmann U. Educational level and risk of chronic kidney disease: longitudinal data from the prevend study. Nephrol Dial Transplant. (2020) 35:1211-8. doi: $10.1093 /$ ndt/gfy361

54. Iwata A, Iwatsubo T, Ihara R, Suzuki K, Matsuyama Y, Tomita N, et al. Effects of sex, educational background, and chronic kidney disease grading on longitudinal cognitive and functional decline in patients in the japanese Alzheimer's disease neuroimaging initiative study. Alzheimers Dement. (2018) 4:765-74. doi: 10.1016/j.trci.2018.06.008

55. Durrani R, Friedrich MG, Schulze KM, Awadalla P, Balasubramanian K, Black SE, et al. Effect of cognitive reserve on the association of vascular brain injury with cognition: Analysis of the PURE and CAHHM studies. Neurology. (2021) 97:e1707-16. doi: 10.1212/WNL.0000000000012765

56. Whitmer RA, Sidney S, Selby J, Johnston SC, Yaffe K. Midlife cardiovascular risk factors and risk of dementia in late life. Neurology. (2005) 64:277-81. doi: 10.1212/01.WNL.0000149519.47454.F2

57. Skoog I, Lernfelt B, Landahl S, Palmertz B, Andreasson LA, Nilsson L, et al. 15-year longitudinal study of blood pressure and dementia. Lancet. (1996) 347:1141-5. doi: 10.1016/S0140-6736(96)90608-X

58. Norton S, Matthews FE, Barnes DE, Yaffe K, Brayne C. Potential for primary prevention of Alzheimer's disease: An analysis of population-based data. Lancet Neurol. (2014) 13:788-94. doi: 10.1016/S1474-4422(14)70136-X

59. Hughes D, Judge C, Murphy R, Loughlin E, Costello M, Whiteley W, et al. Association of blood pressure lowering with incident dementia or cognitive impairment: A systematic review and meta-analysis. JAMA. (2020) 323:1934-44. doi: 10.1001/jama.2020.4249

60. Yamamoto Y, Nagakane Y, Tomii Y, Akiguchi I. High morning and bedtime home blood pressures strongly predict for post-stroke cognitive impairment. I Stroke Cerebrovasc Dis. (2016) 25:1856-63. doi: 10.1016/j.jstrokecerebrovasdis.2016.04.001

61. Ding J, Sigurethsson S, Jonsson PV, Eiriksdottir G, Meirelles O, Kjartansson $\mathrm{O}$, et al. Space and location of cerebral microbleeds, cognitive decline, and dementia in the community. Neurology. (2017) 88:2089-97. doi: 10.1212/WNL.0000000000003983

62. Petrovitch H, Ross GW, Steinhorn SC, Abbott RD, Markesbery W, Davis $\mathrm{D}$, et al. AD lesions and infarcts in demented and non-demented JapaneseAmerican men. Ann Neurol. (2005) 57:98-103. doi: 10.1002/ana.20318

63. Langbaum JB, Chen K, Launer LJ, Fleisher AS, Lee W, Liu X, et al. Blood pressure is associated with higher brain amyloid burden and lower glucose metabolism in healthy late middle-age persons. Neurobiol Aging. (2012) 33:827.e811-829. doi: 10.1016/j.neurobiolaging.2011.06.020

64. McGrath ER, Beiser AS, DeCarli C, Plourde KL, Vasan RS, Greenberg SM, et al. Blood pressure from mid- to late life and risk of incident dementia. Neurology. (2017) 89:2447-54. doi: 10.1212/WNL.0000000000004741

65. Walker KA, Sharrett AR, Wu A, Schneider ALC, Albert M, Lutsey PL, et al. Association of midlife to late-life blood pressure patterns with incident dementia. JAMA. (2019) 322:535-45. doi: 10.1001/jama.2019.10575

66. Muntner P, Anderson A, Charleston J, Chen Z, Ford V, Makos G, et al. Hypertension awareness, treatment, and control in adults with CKD: results from the chronic renal insufficiency cohort (CRIC) study. Am J Kidney Dis. (2010) 55:441-51. doi: 10.1053/j.ajkd.2009.09.014

67. Kurella Tamura M, Gaussoin SA, Pajewski NM, Chelune GJ, Freedman BI, Gure TR, et al. Kidney disease, intensive hypertension treatment, and risk for dementia and mild cognitive impairment: the systolic blood pressure intervention trial. J Am Soc Nephrol. (2020) 31:2122-32. doi: 10.1681/ASN.2020010038

68. Pendlebury ST, Rothwell PM. Prevalence, incidence, and factors associated with pre-stroke and post-stroke dementia: a systematic 
review and meta-analysis. Lancet Neurol. (2009) 8:1006-18. doi: 10.1016/S1474-4422(09)70236-4

69. Ninomiya T, Perkovic V, Verdon C, Barzi F, Cass A, Gallagher M, et al. Proteinuria and stroke: a meta-analysis of cohort studies. Am J Kidney Dis. (2009) 53:417-25. doi: 10.1053/j.ajkd.2008.08.032

70. Major RW, Cheng MRI, Grant RA, Shantikumar S, Xu G, Oozeerally I, et al. Cardiovascular disease risk factors in chronic kidney disease: a systematic review and meta-analysis. PLoS ONE. (2018) 13:e0192895. doi: 10.1371/journal.pone.0192895

71. Plantinga LC, Johansen K, Crews DC, Shahinian VB, Robinson BM, Saran R, et al. Association of CKD with disability in the United States. Am J Kidney Dis. (2011) 57:212-27. doi: 10.1053/j.ajkd.2010.08.016

72. Winkelmayer WC, Patrick AR, Liu J, Brookhart MA, Setoguchi S. The increasing prevalence of atrial fibrillation among hemodialysis patients. J Am Soc Nephrol. (2011) 22:349-57. doi: 10.1681/ASN.2010050459

73. Kumai Y, Kamouchi M, Hata J, Ago T, Kitayama J, Nakane H, et al. Proteinuria and clinical outcomes after ischemic stroke. Neurology. (2012) 78:1909-15. doi: 10.1212/WNL.0b013e318259e110

74. van Uden IW, van der Holst HM, Tuladhar AM, van Norden AG, de Laat KF, Rutten-Jacobs LC, et al. White matter and hippocampal volume predict the risk of dementia in patients with cerebral small vessel disease: the RUN DMC study. J Alzheimers Dis. (2016) 49:863-73. doi: 10.3233/JAD-150573

75. Shi Y, Thrippleton MJ, Makin SD, Marshall I, Geerlings MI, de Craen AJM, et al. Cerebral blood flow in small vessel disease: a systematic review and meta-analysis. J Cereb Blood Flow Metab. (2016) 36:1653-67. doi: $10.1177 / 0271678 \times 16662891$

76. Brickman AM, Guzman VA, Gonzalez-Castellon M, Razlighi Q, Gu Y, Narkhede A, et al. Cerebral autoregulation, beta amyloid, and white matter hyperintensities are interrelated. Neurosci Lett. (2015) 592:54-8. doi: 10.1016/j.neulet.2015.03.005

77. Thal DR, Attems J, Ewers M. Spreading of amyloid, tau, and microvascular pathology in Alzheimer's disease: Findings from neuropathological and neuroimaging studies. J Alzheimers Dis. (2014) 42 Suppl 4:S421-429. doi: 10.3233/JAD-141461

78. Weller RO, Subash M, Preston SD, Mazanti I, Carare RO. Perivascular drainage of amyloid-beta peptides from the brain and its failure in cerebral amyloid angiopathy and Alzheimer's disease. Brain Pathol. (2008) 18:253-66. doi: 10.1111/j.1750-3639.2008.00133.x

79. Toyoda K. Cerebral small vessel disease and chronic kidney disease. J Stroke. (2015) 17:31-7. doi: 10.5853/jos.2015.17.1.31

80. Zong L, Yao M, Ni J, Zhou L, Yuan J, Peng B, et al. Kidney function is associated with severity of white matter hyperintensity in patients with acute ischemic stroke/tia. BMC Neurol. (2016) 16:193. doi: 10.1186/s12883-016-0714-0

81. Makin SD, Cook FA, Dennis MS, Wardlaw JM. Cerebral small vessel disease and renal function: Systematic review and meta-analysis. Cerebrovasc Dis. (2015) 39:39-52. doi: 10.1159/000369777

82. Xiao L, Lan W, Sun W, Dai Q, Xiong Y, Li L, et al. Chronic kidney disease in patients with lacunar stroke: Association with enlarged perivascular spaces and total magnetic resonance imaging burden of cerebral small vessel disease. Stroke. (2015) 46:2081-6. doi: 10.1161/STROKEAHA.114.008155

83. Peng Q, Sun W, Liu W, Liu R, Huang Y. Longitudinal relationship between chronic kidney disease and distribution of cerebral microbleeds in patients with ischemic stroke. J Neurol Sci. (2016) 362:1-6. doi: $10.1016 /$ j.jns.2016.01.015

84. Naganuma T, Uchida J, Tsuchida K, Takemoto Y, Tatsumi S, Sugimura K, et al. Silent cerebral infarction predicts vascular events in hemodialysis patients. Kidney Int. (2005) 67:2434-9. doi: 10.1111/j.1523-1755.2005.00351.x

85. Kobayashi M, Hirawa N, Yatsu K, Kobayashi Y, Yamamoto Y, Saka S, et al. Relationship between silent brain infarction and chronic kidney disease. Nephrol Dial Transplant. (2009) 24:201-7. doi: 10.1093/ndt/gfn419

86. Holliday EG, Traylor M, Malik R, Bevan S, Maguire J, Koblar SA, et al. Polygenic overlap between kidney function and large artery atherosclerotic stroke. Stroke. (2014) 45:3508-13. doi: 10.1161/STROKEAHA.114.006609

87. Yao H, Araki Y, Takashima Y, Uchino A, Yuzuriha T, Hashimoto M. Chronic kidney disease and subclinical brain infarction increase the risk of vascular cognitive impairment: the Sefuri study. J Stroke
Cerebrovasc Dis. (2017) 26:420-4. doi: 10.1016/j.jstrokecerebrovasdis.2016. 10.002

88. Sarnak MJ, Tighiouart H, Scott TM, Lou KV, Sorensen EP, Giang LM, et al. Frequency of and risk factors for poor cognitive performance in hemodialysis patients. Neurology. (2013) 80:471-80. doi: 10.1212/WNL.0b013e31827fof7f

89. O'Brien JT, Erkinjuntti T, Reisberg B, Roman G, Sawada T, Pantoni L, et al. Vascular cognitive impairment. Lancet Neurol. (2003) 2:89-98. doi: 10.1016/S1474-4422(03)00305-3

90. Chatterjee S, Peters SA, Woodward M, Mejia Arango S, Batty GD, Beckett N, et al. Type 2 diabetes as a risk factor for dementia in women compared with men: A pooled analysis of 2. 3 million people comprising more than 100,000 cases of dementia. Diabetes Care. (2016) 39:300-7. doi: 10.2337/dc15-1588

91. Barbiellini Amidei C, Fayosse A, Dumurgier J, Machado-Fragua MD, Tabak AG, van Sloten T, et al. Association between age at diabetes onset and subsequent risk of dementia. JAMA. (2021) 325:1640-9. doi: 10.1001/jama.2021.4001

92. Cunnane SC, Trushina E, Morland C, Prigione A, Casadesus G, Andrews $\mathrm{ZB}$, et al. Brain energy rescue: an emerging therapeutic concept for neurodegenerative disorders of ageing. Nat Rev Drug Discov. (2020) 19:60933. doi: 10.1038/s41573-020-0072-x

93. Kellar D, Craft S. Brain insulin resistance in Alzheimer's disease and related disorders: mechanisms and therapeutic approaches. Lancet Neurol. (2020) 19:758-66. doi: 10.1016/S1474-4422(20)30231-3

94. Hamed SA. Brain injury with diabetes mellitus: Evidence, mechanisms and treatment implications. Expert Rev Clin Pharmacol. (2017) 10:409-28. doi: 10.1080/17512433.2017.1293521

95. Hobson P, Lewis A, Nair H, Wong S, Kumwenda M. How common are neurocognitive disorders in patients with chronic kidney disease and diabetes? Results from a cross-sectional study in a community cohort of patients in north wales, UK. BMJ Open. (2018) 8:e023520. doi: 10.1136/bmjopen-2018-023520

96. Chang AR, Grams ME, Navaneethan SD. Bariatric surgery and kidney-related outcomes. Kidney Int Rep. (2017) 2:261-70. doi: 10.1016/j.ekir.2017.01.010

97. Friedman AN, Kaplan LM. le Roux CW, Schauer PR. Management of obesity in adults with CKD. J Am Soc Nephrol. (2021) 32:777-90. doi: 10.1681/ASN.2020101472

98. Ma Y, Ajnakina O, Steptoe A, Cadar D. Higher risk of dementia in english older individuals who are overweight or obese. Int J Epidemiol. (2020) 49:1353-65. doi: 10.1093/ije/dyaa099

99. Luchsinger JA, Gustafson DR. Adiposity and Alzheimer's disease. Curr Opin Clin Nutr Metab Care. (2009) 12:15-21. doi: 10.1097/MCO.0b013e32831c8c71

100. Palmer S, Vecchio M, Craig JC, Tonelli M, Johnson DW, Nicolucci A, et al. Prevalence of depression in chronic kidney disease: systematic review and meta-analysis of observational studies. Kidney Int. (2013) 84:179-91. doi: $10.1038 / \mathrm{ki} .2013 .77$

101. Fischer MJ, Xie D, Jordan N, Kop WJ, Krousel-Wood M, Kurella Tamura M, et al. Factors associated with depressive symptoms and use of antidepressant medications among participants in the chronic renal insufficiency cohort (CRIC) and Hispanic-CRIC studies. Am J Kidney Dis. (2012) 60:27-38. doi: 10.1053/j.ajkd.2011.12.033

102. Agganis BT, Weiner DE, Giang LM, Scott T, Tighiouart H, Griffith JL, et al. Depression and cognitive function in maintenance hemodialysis patients. Am J Kidney Dis. (2010) 56:704-12. doi: 10.1053/j.ajkd.2010.04.018

103. Maung SC, El Sara A, Chapman C, Cohen D, Cukor D. Sleep disorders and chronic kidney disease. World J Nephrol. (2016) 5:224-32. doi: $10.5527 /$ wjn.v5.i3.224

104. Wennberg AMV, Wu MN, Rosenberg PB, Spira AP. Sleep disturbance, cognitive decline, and dementia: a review. Semin Neurol. (2017) 37:395-406. doi: $10.1055 / \mathrm{s}-0037-1604351$

105. Plog BA, Nedergaard M. The glymphatic system in central nervous system health and disease: past, present, and future. Annu Rev Pathol. (2018) 13:379-94. doi: 10.1146/annurev-pathol-051217-111018

106. Viggiano D, Wagner CA, Martino G, Nedergaard M, Zoccali C, Unwin R, et al. Mechanisms of cognitive dysfunction in CKD. Nat Rev Nephrol. (2020) 16:452-469. doi: 10.1038/s41581-020-0266-9 
107. Liu AJ, Staffaroni AM, Rojas-Martinez JC, Olney NT, Alquezar-Burillo C, Ljubenkov PA, et al. Association of cognitive and behavioral features between adults with tuberous sclerosis and frontotemporal dementia. JAMA Neurol. (2020) 77:358-66. doi: 10.1001/jamaneurol.2019.4284

108. Körver S, Geurtsen GJ, Hollak CEM, van Schaik IN, Longo MGF, Lima $\mathrm{MR}$, et al. Predictors of objective cognitive impairment and subjective cognitive complaints in patients with fabry disease. Sci Rep. (2019) 9:188. doi: 10.1038/s41598-018-37320-0

109. Caterino M, Zacchia M, Costanzo M, Bruno G, Arcaniolo D, Trepiccione $\mathrm{F}$, et al. Urine proteomics revealed a significant correlation between urine-fibronectin abundance and estimated-GFR decline in patients with Bardet-Biedl syndrome. Kidney Blood Press Res. (2018) 43:389-405. doi: 10.1159/000488096

110. Verbitsky M, Kogon AJ, Matheson M, Hooper SR, Wong CS, Warady BA, et al. Genomic disorders and neurocognitive impairment in pediatric CKD. J Am Soc Nephrol. (2017) 28:2303-9. doi: 10.1681/ASN.2016101108

111. Groopman EE, Marasa M, Cameron-Christie S, Petrovski S, Aggarwal VS, Milo-Rasouly H, et al. Diagnostic utility of exome sequencing for kidney disease. N Engl J Med. (2019) 380:142-51. doi: 10.1056/NEJMoa1806891

112. Connaughton DM, Kennedy C, Shril S, Mann N, Murray SL, Williams PA, et al. Monogenic causes of chronic kidney disease in adults. Kidney Int. (2019) 95:914-28. doi: 10.1016/j.kint.2018.10.031

113. Wuttke M, Li Y, Li M, Sieber KB, Feitosa MF, Gorski M, et al. A catalog of genetic loci associated with kidney function from analyses of a million individuals. Nat Genet. (2019) 51:957-72. doi: 10.1038/s41588-019-0407-x

114. Marini S, Georgakis MK, Chung J, Henry JQA, Dichgans M, Rosand J, et al. Genetic overlap and causal inferences between kidney function and cerebrovascular disease. Neurology. (2020) 94:e2581-91. doi: 10.1212/WNL.0000000000009642

115. De Deyn PP, Vanholder R, Eloot S, Glorieux G. Guanidino compounds as uremic (neuro)toxins. Semin Dial. (2009) 22:340-5. doi: 10.1111/j.1525-139X.2009.00577.x

116. Li C, Wu X, Liu S, Zhao Y, Zhu J, Liu K. Roles of neuropeptide y in neurodegenerative and neuroimmune diseases. Front Neurosci. (2019) 13:869. doi: 10.3389/fnins.2019.00869

117. Zoccali C, D’Arrigo G, Leonardis D, Pizzini P, Postorino M, Tripepi $\mathrm{G}$, et al. Neuropeptide $\mathrm{y}$ predicts cardiovascular events in chronic kidney disease patients: a cohort study. J Hypertens. (2019) 37:1359-65. doi: 10.1097/HJH.0000000000002030

118. Kaysen GA. The microinflammatory state in uremia: Causes and potential consequences. J Am Soc Nephrol. (2001) 12:1549-57. doi: 10.1681/ASN.V1271549

119. Shlipak MG, Fried LF, Crump C, Bleyer AJ, Manolio TA, Tracy $\mathrm{RP}$, et al. Elevations of inflammatory and procoagulant biomarkers in elderly persons with renal insufficiency. Circulation. (2003) 107:87-92. doi: 10.1161/01.CIR.0000042700.48769.59

120. Szerlip HM, Edwards ML, Williams BJ, Johnson LA, Vintimilla RM, O'Bryant SE. Association between cognitive impairment and chronic kidney disease in Mexican Americans. J Am Geriatr Soc. (2015) 63:2023-8. doi: 10.1111 /jgs. 13665

121. Kurella Tamura M, Tam K, Vittinghoff E, Raj D, Sozio SM, Rosas SE, et al. Inflammatory markers and risk for cognitive decline in chronic kidney disease: The CRIC study. Kidney Int Rep. (2017) 2:192-200. doi: 10.1016/j.ekir.2016.10.007

122. Ghoshal S, Parikh A. Dialysis-associated neurovascular injury (DANI) in acute brain injury: Practical considerations for intermittent dialysis in the neuro-ICU. Clin J Am Soc Nephrol. (2021) 16:1110-2. doi: 10.2215/CJN.15000920

123. Kelly DM, Ademi Z, Doehner W, Lip GYH, Mark P, Toyoda K, et al. Chronic kidney disease and cerebrovascular disease: Consensus and guidance from a KDIGO controversies conference. Stroke. (2021) 52:e32846. doi: 10.1161/STROKEAHA.120.029680

124. Galons JP, Trouard T, Gmitro AF, Lien YH. Hemodialysis increases apparent diffusion coefficient of brain water in nephrectomized rats measured by isotropic diffusion-weighted magnetic resonance imaging. J Clin Invest. (1996) 98:750-5. doi: 10.1172/JCI118847

125. Silver SM, Sterns RH, Halperin ML. Brain swelling after dialysis: Old urea or new osmoles? Am J Kidney Dis. (1996) 28:1-13. doi: 10.1016/S0272-6386(96)90124-9

126. Polinder-Bos HA, Garcia DV, Kuipers J, Elting JWJ, Aries MJH, Krijnen WP, et al. Hemodialysis induces an acute decline in cerebral blood flow in elderly patients. J Am Soc Nephrol. (2018) 29:1317-25. doi: 10.1681/ASN.2017101088

127. MacEwen C, Sutherland S, Daly J, Pugh C, Tarassenko L. Relationship between hypotension and cerebral ischemia during hemodialysis. J Am Soc Nephrol. (2017) 28:2511-20. doi: 10.1681/ASN.2016060704

128. Findlay MD, Dawson J, Dickie DA, Forbes KP, McGlynn D, Quinn T, et al. Investigating the relationship between cerebral blood flow and cognitive function in hemodialysis patients. J Am Soc Nephrol. (2019) 30:147-58. doi: 10.1681/ASN.2018050462

129. Tian DY, Cheng Y, Zhuang ZQ, He CY, Pan QG, Tang MZ, et al. Physiological clearance of amyloid-beta by the kidney and its therapeutic potential for Alzheimer's disease. Mol Psychiatry. (2021). doi: 10.1038/s41380-02101073-6

130. Levy E, Sastre M, Kumar A, Gallo G, Piccardo P, Ghetti B, et al. Codeposition of cystatin $\mathrm{C}$ with amyloid-beta protein in the brain of alzheimer disease patients. J Neuropathol Exp Neurol. (2001) 60:94-104. doi: $10.1093 /$ jnen/60.1.94

131. Jin WS, Shen LL, Bu XL, Zhang WW, Chen SH, Huang ZL, et al. Peritoneal dialysis reduces amyloid-beta plasma levels in humans and attenuates Alzheimer-associated phenotypes in an APP/PS1 mouse model. Acta Neuropathol. (2017) 134:207-20. doi: 10.1007/s00401-0171721-y

132. Sakai K, Senda T, Hata R, Kuroda M, Hasegawa M, Kato M, et al. Patients that have undergone hemodialysis exhibit lower amyloid deposition in the brain: Evidence supporting a therapeutic strategy for Alzheimer's disease by removal of blood amyloid. J Alzheimers Dis. (2016) 51:997-1002. doi: 10.3233/JAD-151139

133. Tholen S SC, Chmielewski S, Förstl H, Heemann U, Baumann M, Steubl D, et al. Reduction of amyloid- $\beta$ plasma levels by hemodialysis: an anti-amyloid treatment strategy? J Alzheimers Dis. (2016) 50:791-6. doi: $10.3233 /$ JAD-150662

Conflict of Interest: The authors declare that the research was conducted in the absence of any commercial or financial relationships that could be construed as a potential conflict of interest.

Publisher's Note: All claims expressed in this article are solely those of the authors and do not necessarily represent those of their affiliated organizations, or those of the publisher, the editors and the reviewers. Any product that may be evaluated in this article, or claim that may be made by its manufacturer, is not guaranteed or endorsed by the publisher.

Copyright (c) 2022 Kelly and Rothwell. This is an open-access article distributed under the terms of the Creative Commons Attribution License (CC BY). The use, distribution or reproduction in other forums is permitted, provided the original author(s) and the copyright owner(s) are credited and that the original publication in this journal is cited, in accordance with accepted academic practice. No use, distribution or reproduction is permitted which does not comply with these terms. 